\title{
Stabilizing a Gimbal Platform using Self-Tuning Fuzzy PID Controller
}

\author{
Nourallah Ghaeminezhad \\ Collage Of Automation \\ Engineering \\ Nuaa \\ Nanjing \\ China
}

\author{
Wang Daobo \\ Collage Of Automation \\ Engineering \\ Nuaa \\ Nanjing \\ China
}

\author{
Fahad Farooq \\ Collage Of Automation \\ Engineering \\ Nuaa \\ Nanjing \\ China
}

\begin{abstract}
The aim of the inertial stabilization system is to stabilize the sensor's line of sight (LOS) toward a target while is isolating the sensor against the disturbances which are caused by the operating environment. The purpose which this paper is following is a model of control servo system for an inertially stabilized gimbal mechanism to improve the performance of system which is using only PID controller by finding a way to tune the PID gains online, for this purpose a self-tuning Fuzzy PID type controller is used. First the relationships that governs gimbals torque will be derived from Newton's law under consideration of the dynamic mass unbalance and base angular motion. The next step is construction of stabilization loop through designing the proposed self-tuning Fuzzy-PID controller. For simulation and investigate the system performance in different cases of controller, the Matlab/Simulink is used and Based on different performance criteria a comparison study is made. Based on the results in different conditions on proposed controller the system performance is improved. The simulation result shows improvement on transient and the steady-state performance.
\end{abstract}

\section{Keywords}

Servo control system, inertially stabilized platform, intelligent control, self-tuning Fuzzy PID, Matlab/Simulink.

\section{INTRODUCTION}

An inertial stabilized platform (ISP) or well-known gimbal system is to stabilize the platform which camera or any optical sensing equipment mounted on that, to track a moving or fixed object. The equipment typically is mounted on the moving carrier like UAV or Helicopter. Although requirements for ISPs vary widely depending on the application, they all have a common goal, which is to hold or control the line of sight (LOS) of one object relative to another object or inertial space. [1]

In this paper a tracking system's LOS with nonlinear disturbance is considered. The aim is to track the input velocity command, when the disturbance due to movement of base comes to system. In this paper the pitch (elevation) loop is considered, and it is tried to stabilize one axis platform using a proper controller. Then, it opens a way toward thinking of how to make such a system stable and it can be studied for other axis (yaw) similarly.

Concerning the control system, although the researchers tried to utilize and apply many different modern techniques to control servo systems, the conventional PID and its constructors are still the most used approach due to their simple structure, cheap costs, simple design and high performance [2], but when there are nonlinear disturbances or uncertain situation like what in the movement of UAV, the PID gains must tune online during the control. This paper investigates a self-tuning Fuzzy PID controller to deal with mentioned problems. The use of this controller has been proved as an effective tool of many nonlinear systems. [3]- [4]

Our paper is divided to two main parts, first is presenting a stabilized gimbal control system in order to simplify the picture of the gimbal platform.

And secondly to introduce a self-tuning fuzzy PID controller for related axis gimbal system.

\section{FORMULATE THE MODEL}

\subsection{Problem Statement}

In principal, all the required thing to prevent an object from rotating with respect to inertial space is to ensure that applied torque is zero. According to, Newton's second law if a net torque $\mathrm{T}$ is applied to a homogenous rigid mass having a moment of inertia $J$, then the body develops an angular acceleration $\alpha,[1]$, that's evident in : T=J. $\alpha$ (1)

The block diagram in Figure 1 shows the gimbal stabilization system.

In this diagram it is tried to null the differences between the rate command input and angular rate of the gimbal, so the proper amount of torque must be forced to gimbal. From Figure 1, it can be seen that:

$$
\frac{\omega_{E s}}{T}=\frac{1}{J s}, \quad T=J \omega_{E S} S=J \omega_{E S}^{\cdot}, \quad T=J \alpha,
$$

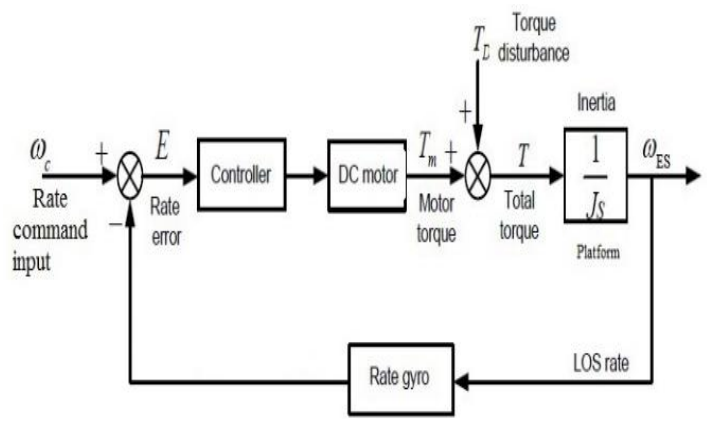

Figure 1 Control loop of LOS stabilized platform

Therefore, the paper problem can be briefed into the servo control platform that takes part into two main object. one is command tracking which says about how well the output speed conforms the input command speed. Another is rejection of disturbances that might be anything from the platform movement to rate gyro noise. 


\subsection{LOOP BLOCK CONSTRUCTION}

This stabilized loop consists of dc motor, rate gyro and platform with interference of a torque namely disturbance torque which will be formulated.

\subsubsection{Platform}

To formulate the platform (motor load that is attached to the shaft motor) we use load moment of inertia that directly is related to mass and radius of the platform:

$J_{L}=\frac{1}{2} M r^{2},(2)$ in this project $\mathrm{m}=2 \mathrm{~kg}$ and radius is $10 \mathrm{~cm}$ so $J_{L}=1 * 10^{-2} \mathrm{kgm}^{3}$

\subsubsection{Motor}

DC motor is widely preferred for high performance systems with lowest torque ripple, fast dynamic torque, fast responses, high efficiency and well inertia [5].

The following equations show the dynamic performance of a dc motor and the equivalent circuit is shown in the figure2:

$$
\begin{aligned}
& u_{a}(t)=R_{a} I_{a}(t)+L_{a} \frac{d I_{a}(t)}{d t}+e(t),(3) \\
& e(t)=k_{e} \omega_{m(t)},(4) \\
& T_{m}(t)=k_{T M} I_{a}(t),(5) \\
& T_{m}(t)=J_{m} \frac{d \omega_{m}}{d t}+a_{m} \omega_{m(t)}+T_{D(t)},(6)
\end{aligned}
$$

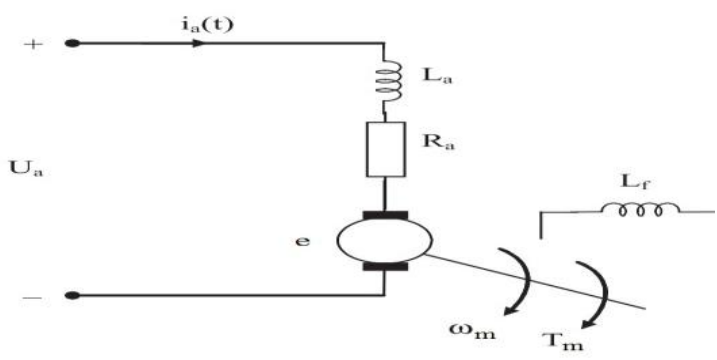

Figure 1. Equivalent circuit of DC motor

by applying the Laplace transform to above equations and considering the initial condition as zero, the model of DC motor can be expressed as shown in Fig. 3

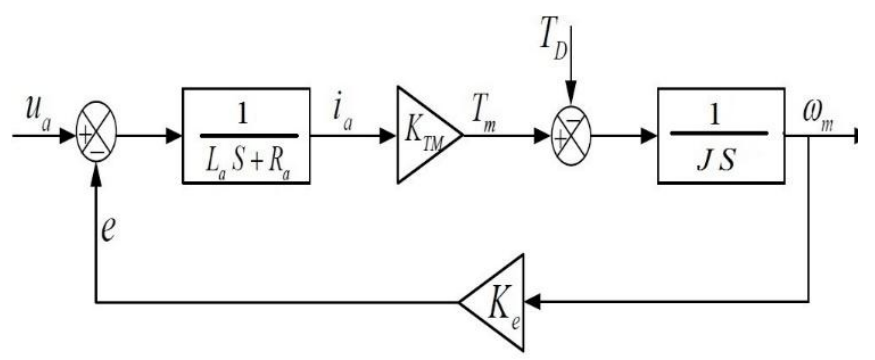

Figure 2. Block diagram of DC Motor

Supposing $T_{D}=0$, it can be concluded that the transfer function of the dc motor is :

$$
G_{m(s)}=\frac{\omega_{m(s)}}{u_{a(s)}}=\frac{K_{t}}{L_{a} J S^{2}+R_{a} J s+\left(k_{b} \cdot k_{t}\right)},
$$

The characteristics of the DC motor in this paper is mentioned as below:

$$
\begin{aligned}
& R_{a}=5.5 \Omega \\
& L_{a}=1.2 \mathrm{mh} \\
& K_{b}=0.650 \mathrm{v} / \mathrm{rad} / \mathrm{sec} \text { (back emf constant) } \\
& j_{m}=0.0025 \mathrm{kgm}^{2} \text { (Motor moment of inertia) } \\
& K_{t}=0.720 \mathrm{Nm} / A \text { (Torque constant) } \\
& J=j_{m}+j_{l}=0.0025+0.01=0.0125 \mathrm{kgm}^{2} \text { (total moment of } \\
& \text { inertia) }
\end{aligned}
$$

Therefore, transfer function of DC motor can be obtained by putting them in equation (7):

$$
G_{m(s)}=\frac{240}{s^{2}+4.6 s+156}
$$

\subsubsection{RATE GYRO}

To define a rate gyro the following transfer function is used [6]:

$G_{\text {gyro }(s)}=\frac{\omega_{n}^{2}}{s^{2}+2 \delta \omega_{n} s+\omega_{n}^{2}},(8)$

CRG20-12 rate gyroscope has been used in this paper, and according to characteristics:

$\omega_{n}=40 H Z$ and $\delta=0.8$

Therefore, using them in (8): $G_{\text {gyro }(s)}=\frac{1600}{s^{2}+64 s+1600}$

\section{GIMBAL SPECIFICATION}

A simple inertial gimbal axis is shown in figure 4 :

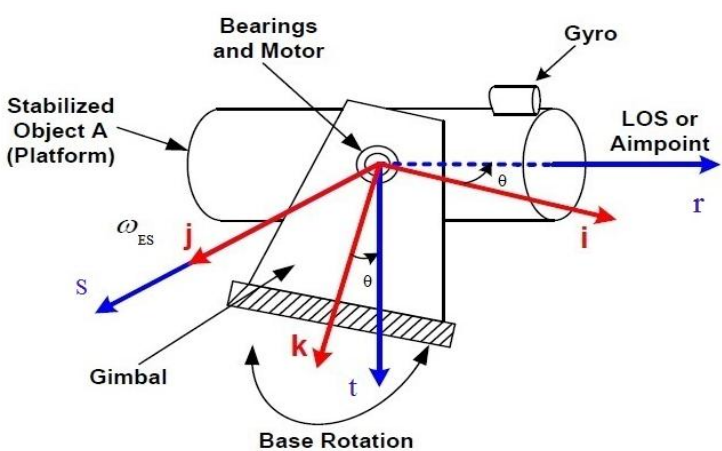

Figure 3. Gimbal mechanism

According to what has been done in [7] and based on fig2, two frames are discussed, frame $\mathrm{O}$ on the base (body) with axes (i, j, $\mathrm{k})$ and frame $\mathrm{E}$ on the gimbal with axes $(\mathrm{r}, \mathrm{s}, \mathrm{t})$, which present the pitch axis and stabilized object. Transformation matric between frames $\mathrm{O}$ and $\mathrm{E}$ is shown in (10) and (11), while $\theta$ is the gimbal angle about the $\mathrm{j}$ axis.

$T_{E O}=\left[\begin{array}{ccc}\cos \theta & 0 & -\sin \theta \\ 0 & 1 & 0 \\ \sin \theta & 0 & \cos \theta\end{array}\right]$ (9)

The angular velocity vector of frame $\mathrm{O}$ and $\mathrm{E}$ about their inertia axis are respectively:

$$
\omega_{O}=\left[\begin{array}{c}
\omega_{O i} \\
\omega_{O j} \\
\omega_{O k}
\end{array}\right] \text { and } \omega_{E}=\left[\begin{array}{c}
\omega_{E r} \\
\omega_{E s} \\
\omega_{E t}
\end{array}\right]
$$

By applying (10) on (11)

The angular velocities of the stabilized object are obtained as:

$$
\begin{aligned}
& \omega_{E r}=\omega_{O i} \cos \theta-\omega_{O k} \sin \theta \\
& \omega_{E s}=\omega_{O j}+\dot{\theta}(12) \\
& \omega_{E t}=\omega_{O i} \sin \theta+\omega_{O k} \cos \theta
\end{aligned}
$$

Based on dynamic characteristics of the gimbal in system, inertia matrix of the pitch gimbal is: 
$J_{E}=\left[\begin{array}{lll}J_{r} & D_{r s} & D_{r t} \\ D_{r s} J_{s} & D_{t s} \\ D_{r t} D_{t s} & J_{t}\end{array}\right]$

(14) Where $J_{r}, J_{s}, J_{t}$ are gimbal moments of inertia about $\mathrm{r}, \mathrm{s}$ and $\mathrm{t}$ axis; and $D_{r t}, D_{r s}, D_{t s}$ are gimbal moments product of inertia.

According to [7][8], in fig $1, T_{D}$, can be calculated as :

$T_{D}=\left(J_{t}-J_{r}\right) \omega_{E i} \omega_{E k}+D_{r t}\left(\omega_{E i}^{2}-\omega_{E k}^{2}\right)-$

$D_{t s}\left(\omega_{E k}^{\cdot}-\omega_{E k} \omega_{E i}\right)-D_{r s}\left(\omega_{E l}+\omega_{E j} \omega_{E k}\right)$

In fig $1, T_{M}$ represents only the motor torque and $T_{D}$ the disturbance torque, so it can be considered the block in figure 5 within the motor and disturbance torques are the inputs to the platform and output is angular velocity of pitch gimbal about $j$ axis(coincident to movement direction of pitch gimbal) which is ,showed with $\omega_{E t}$.

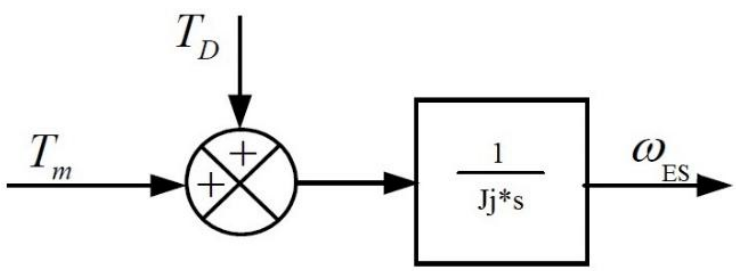

Figure 4 .gimbal block

It must be mentioned that the product of inertia (POI) effect [8], causes the dynamic mass unbalance in systems with nonsymmetrical mass distribution, but in this paper it is assumed that the gimbal has no dynamic unbalance, i.e. $D_{i j}, D_{i k}$ and $D_{k j}=$

\section{CONTROLLER DESIGN}

\subsection{Controller Type}

PID controller is one of the well-known controller that is still being used in industry, while there are some conditions, which it doesn't work well, like when there is nonlinear and uncertain conditions. When there are such problems one of the best ways to solve, is tuning the PID gains manually again, that is not possible in the fast and online applications.in this paper a fuzzy logic method has been used to tune the gains KP, KI and KD according to error e ( $\mathrm{t})$, the difference between commanded input and gyro output signal, and derivative of error de $(t)$, so the system controller is self-tuned PID using fuzzy controller. The general structure diagram of the controller is shown in figure 6 .

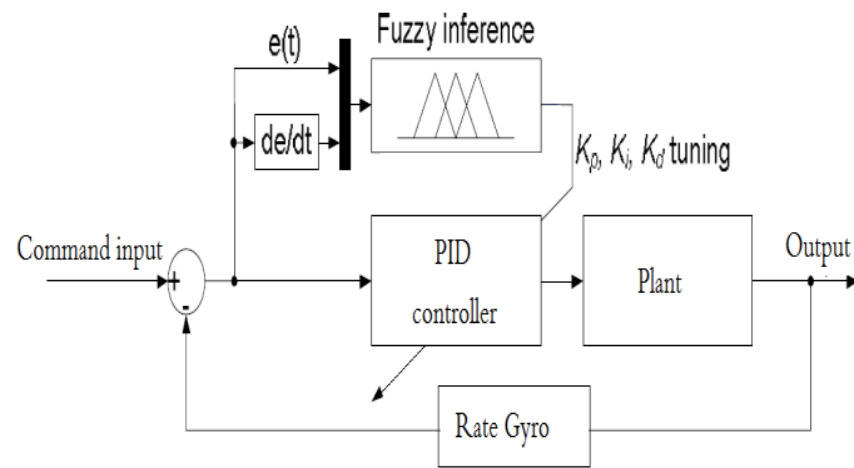

Figure 5 .Structure of Self-Tuning Fuzzy PID Controller

\subsection{Designing the Controller}

The system involves two type of controller namely: PID and fuzzy controller. For the PID part, a conventional PID controller is used, so the related control signal in time domain is:
$u(t)=K_{p} e(t)+K_{i} \int_{0}^{t} e(t) d(t)+K_{d} \frac{d e(t)}{d t}(16)$

Tuning the parameters of PID controller, needs a fuzzy interface that makes a nonlinear transferring from the e $(\mathrm{t})$ and de $(\mathrm{t})$ to the PID gains.

Design a fuzzy controller consists of several parts:

a) Designing inputs and outputs :

The first step for designing a FLC is to identify the input and output variables, which in this paper inputs are e $(\mathrm{t})$, de $(\mathrm{t})$ and outputs are $\mathrm{kp}$, ki and $\mathrm{kd}$, which are used to tune the pid controller.

b) Liguistic variables :

In this step the input and output variables are put in different classes , 7 classes are chosen for both input out output variables ,namely negative $\operatorname{big}(\mathrm{Nb})$, negative medium( $\mathrm{Nm})$, negative small(Ns),zero(Z),positive small(Ps),positive medium(Pm) and positive $\operatorname{big}(\mathrm{Pb})$, while the variation rang of $\operatorname{de}(\mathrm{t})$ is $[-55]$ and $\mathrm{e}(\mathrm{t})$ is [-0.32 0.32].For the output variables $\mathrm{kp}$, ki and $\mathrm{kd}$, the variation range is [0 1]. The functions for linguistic variables for inputs and outputs are triangle membership functions.

\section{c) Fuzzy rull bace}

The Fuzzy rules change depending on type of controller and plant. These rules are obtained according to experiment to get the high performance control system. Properties of PID controller, nonlinear disturbance error and characteristics of DC motor and gimbal payload are the impact factors to choose these rules base. The fuzzy inference method used in this paper is MAX- MIN and the defuzzification method is centroid. The rules for the $\mathrm{kp}$ and $\mathrm{ki}$ are shown in the table 1 , and for the $\mathrm{kd}$ in table 2 .

Table.1 Fuzzy rules of kp and ki

\begin{tabular}{|l|l|l|l|l|l|l|l|}
\hline e/de & NB & NM & NS & Z & PS & PM & PB \\
\hline NB & NB & NB & NM & NM & NS & Z & Z \\
\hline NM & NB & NB & NM & NS & NS & Z & Z \\
\hline NS & NB & NM & NM & NS & Z & PS & PS \\
\hline Z & NM & NM & NS & Z & PS & PS & PM \\
\hline PS & NS & Z & PS & PS & PM & PB & PB \\
\hline PM & Z & Z & PS & PS & PM & PB & PB \\
\hline PB & Z & Z & PS & PM & PM & PB & PB \\
\hline
\end{tabular}


Table.2 Fuzzy rules of kd

\begin{tabular}{|l|l|l|l|l|l|l|l|}
\hline e/de & NB & NM & NS & Z & PS & PM & PB \\
\hline NB & PS & PS & Z & PS & Z & PM & PB \\
\hline NM & NS & NS & NS & Z & Z & PS & PS \\
\hline NS & NM & NM & NS & NS & PS & PS & PM \\
\hline Z & NB & NM & NM & NM & Z & PM & PM \\
\hline PS & NM & NM & NS & NS & NS & PS & PS \\
\hline PM & NB & NS & NS & NM & Z & PM & PS \\
\hline PB & PM & Z & NS & $Z$ & $Z$ & PB & PM \\
\hline
\end{tabular}

The outputs of Fuzzy controller are PID normalized parameters, so when they are going to be used with the PID controller, they must be denormalize using following equations [9]:

$$
\begin{aligned}
& K P=\frac{k p-k p_{\min }}{k p_{\max }-k p_{\min }}(17), \quad K I=\frac{k i-k i_{\min }}{k i_{\max }-k i_{\min }}(18), \\
& K D=\frac{k d-k d_{\min }}{k d_{\max }-k d_{\min }}(19)
\end{aligned}
$$

Interval of PID gains, [min, max], can be obtained by experiment. Here in considered model the acceptable variant ranges are: kp: [0.5, 1.5], ki: [1,3] and kd: [0.001, 0.1];

Therefore, by applying them on (17), (18) and (19) we have: $\mathrm{KP}=k p+0.5(20)$

$\mathrm{KI}=2 k i+1(21)$

$\mathrm{KD}=0.009 k d+0.001$

The denormalized block function in Fig.8 implements these equations to the model.

\section{SIMULATIONS AND COMPARISON}

\subsection{Simulation}

In this part, by using the simulink/Matlab, the effectiveness of discussed controller is evaluated to show, how new self-tuning fuzzy PID controller is in comparison with the PID controller, in the considered LOS model.

Fig.7 and Fig.8 show the Simulink model of system, while using PID and self-tuning Fuzzy PID controllers:

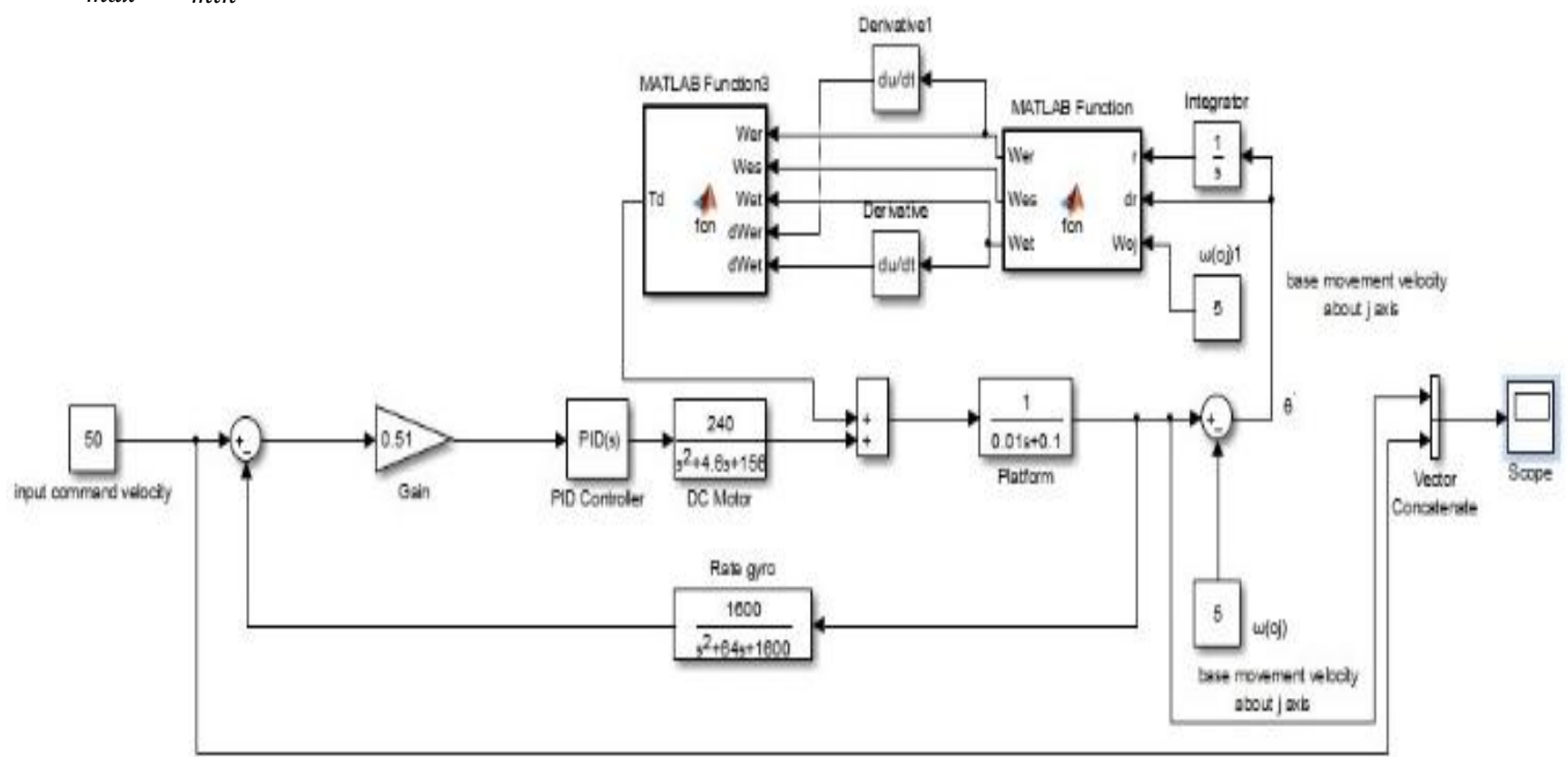

Figure 6. Simulink model, using PID controller 


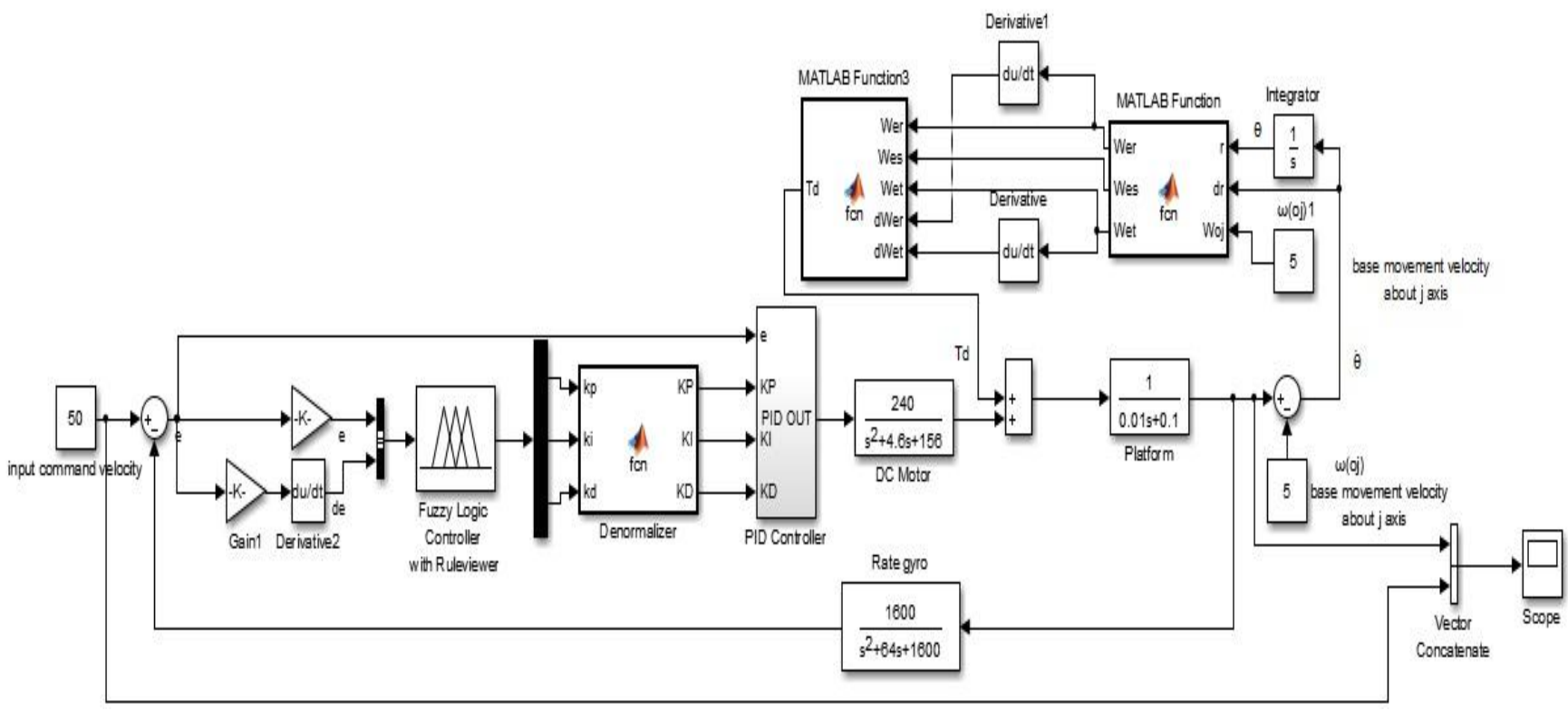

Figure 7 .Simulink model using self-tuning fuzzy PID controller

During simulation, the command input velocity

$\omega_{c}=50 \mathrm{deg} / \mathrm{sec}$, and base movement is considered with taking the $\omega_{O i}=10 \mathrm{deg} / \mathrm{sec}$ and $\omega_{O k}=15 \mathrm{deg} / \mathrm{sec}$, while $\omega_{O j}$ changes, and 3 different $\omega_{O j}$ (in this paper the study is on the pitch gimbal, so the base movement is considered only on $\mathrm{j}$ axis) are tested.

The results of simulation are shown in Fig.9 for $\omega_{0 j}=$ $5 \mathrm{deg} / \mathrm{sec}$; Fig.10 for $\omega_{O j}=30 \mathrm{deg} / \mathrm{sec}$ and Fig.11 for $\omega_{O j}=60 \mathrm{deg} / \mathrm{sec}$.

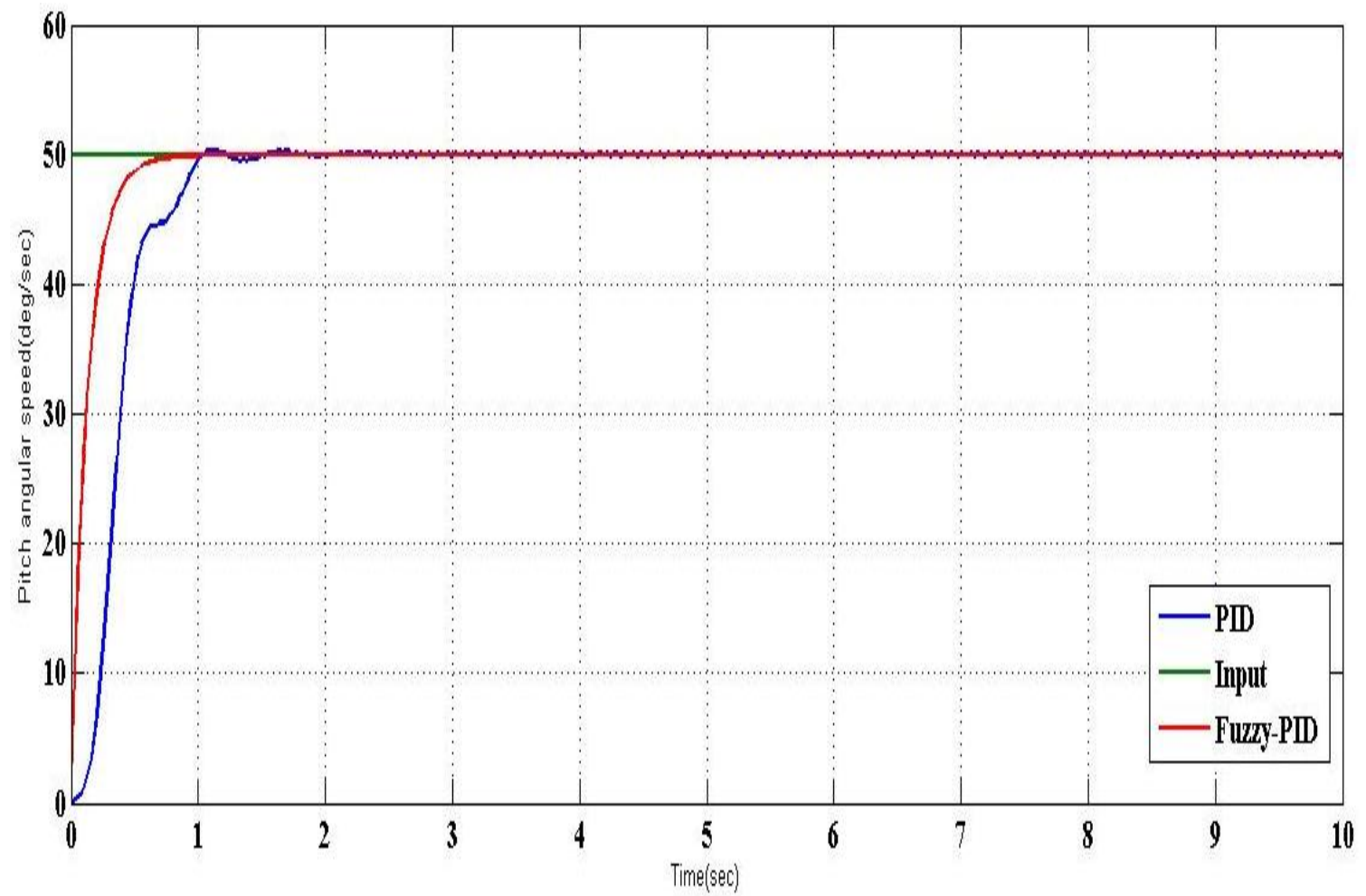

Figure 8 command following of LOS system with PID and self-tuning fuzzy PID controller when $\omega_{0 j}=5 \mathrm{deg} / \mathrm{sec}$ 


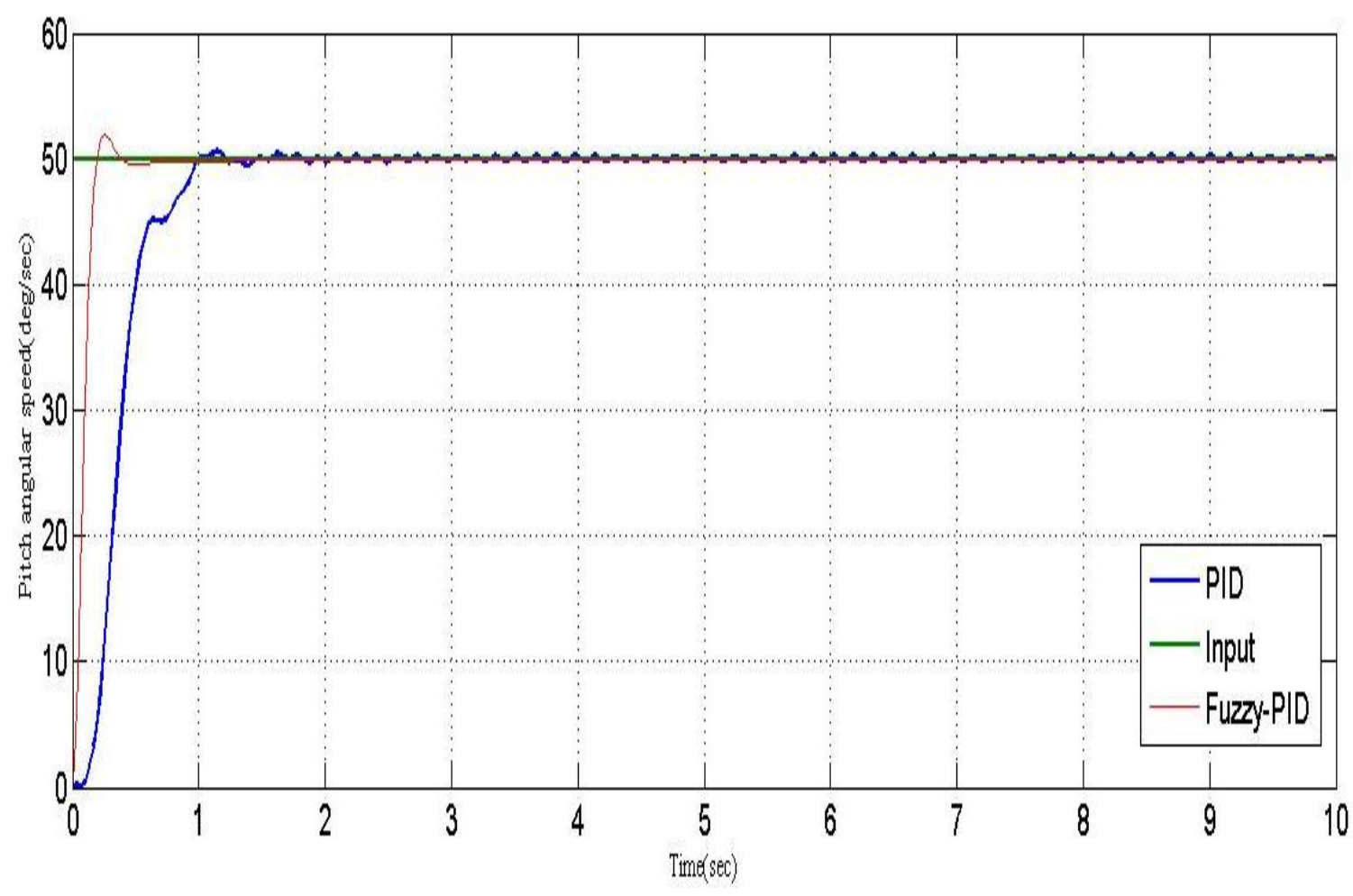

Figure 9. Command following of LOS system with PID and self-tuning fuzzy PID controller when $\omega_{0 j}=30 \mathrm{deg} / \mathrm{sec}$

Table 3, illustrates the values that show the time response of the adjusted controllers in the discussed servo control system.

The system to be acceptable must satisfy these requirements:

- $\quad$ Rising time $(\mathrm{sec}) ; t_{r} \leq 0.15 \mathrm{sec}$

- $\quad$ Settling time(sec); $t_{s} \leq 0.3 \mathrm{sec}$

- $\quad$ Maximum overshot (\%); $M P \leq 20 \%$

Tabel 3. System performance results for two types of controller

\begin{tabular}{|c|c|c|c|c|c|c|}
\hline \multirow{3}{*}{$\begin{array}{c}\begin{array}{c}\omega_{o j} \\
(\mathrm{deg} / \mathrm{sec})\end{array} \\
5 \mathrm{deg} / \mathrm{sec}\end{array}$} & \multirow[b]{2}{*}{ PID } & \multirow{2}{*}{$\begin{array}{l}(\mathrm{sec}) \\
\text { uzzy-PID }\end{array}$} & \multicolumn{2}{|c|}{ MP (\%) } & \multicolumn{2}{|c|}{$t_{s}(\mathrm{sec})$} \\
\hline & & & PID & Fuzzy-PID & PID & Fuzzy-PID \\
\hline & $1.03 \mathrm{sec}$ & $0.93 \mathrm{sec}$ & 0 & 0 & $1.68 \mathrm{sec}$ & $0.98 \mathrm{sec}$ \\
\hline 30deg/sec & $0.94 \mathrm{sec}$ & $0.24 \mathrm{sec}$ & 0 & $16.5 \%$ & $1.45 \mathrm{sec}$ & $1.12 \mathrm{sec}$ \\
\hline $60 \mathrm{deg} / \mathrm{sec}$ & $1.09 \mathrm{sec}$ & $0.39 \mathrm{sec}$ & 0 & $19.8 \%$ & $1.55 \mathrm{sec}$ & $2.15 \mathrm{sec}$ \\
\hline
\end{tabular}




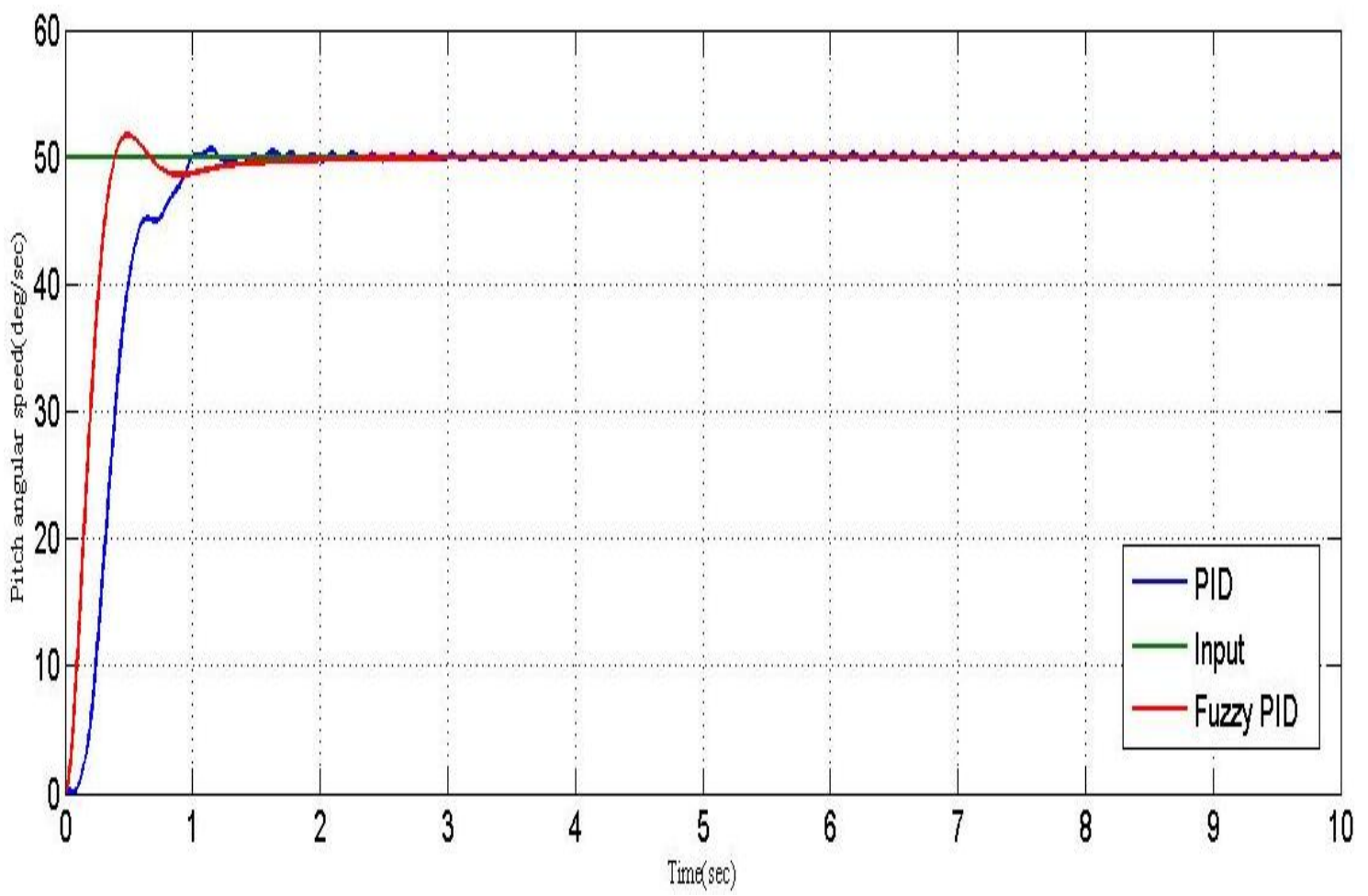

Figure 10 .command following of LOS system with PID and self-tuning fuzzy PID controller when $\omega_{0 j}=60$

\section{DISCUSSION}

The self-tuning fuzzy PID controller acts well for all tested $\omega_{o j}$, and the results confirm an stable behavior of the system whether $\omega_{o j}$, is $\operatorname{less}(5 \mathrm{deg} / \mathrm{sec}$ and $30 \mathrm{deg} / \mathrm{sec})$ or more than $\omega_{c}(60$ $\mathrm{deg} / \mathrm{sec})$. Once more thing that can be understood from the figures is that, as $\omega_{o j}$ increases, the results are evidence of less effectiveness of controllers. Increasing the settling time and maximum over shoot in self-tuning fuzzy PID controlled model; during to rise up of $\omega_{o j}$ confirms that.

\section{CONCLUSION}

Presence of nonlinear condition makes the work hard for the conventional controllers to perform as well as they are expected; but it isn't leading to conclude that there is no way to stabilize a system under nonlinear condition, while they are being used. in this paper it was shown that how the movement of base (body), which the platform is mounted on, makes a gimbal stabilized platform unstable, by accelerating gradually about one axis which is coincident on pitch movement. Then it can be seen a PID controller that lets the system unstable, when the online nonlinear disturbance due to base movement enters. This time is when the fuzzy controller, as an artificial intelligent controller, which was discussed for the first time with professor ZADEH, challenges a way to take the PID controller into consideration in nonlinear system by tuning the PID gains, which makes the controller flexible till it shows a stable performance during a fast rising and settling time, with acceptable maximum overshoot. Generally it can be concluded that, using both conventional and new intelligent kind of controllers together is possible, and it is one solution to make such a nonlinear system stable.

\section{REFERENCES}

[1] Hilkert, J., "Inertially stabilized platform technology concepts and principles", Control Systems, IEEE, Vol. 28, No. 1, 2008, 26-46.J.

[2] Tang, K., Huang, S., Tan, K. and Lee, T., "Combined pid and adaptive nonlinear control for servo mechanical systems", Mechatronics", Vol. 14, No. 6, 2004

[3] R. Babuska, J. Oosterhoff, A. Oudshoorn, P.M.Bruijn, "Fuzzy self-tuning PI control of $\mathrm{pH}$ infermentation, Artificial Intelligence", vol. 15, no. 1, pp. 3-15, 2002.

[4] M. Petrov, I. Ganchev, A. Taneva, -"Fuzzy PID Control for nonlinear plant", IEEE Sym.Intelligent Systems, vol.1, pp.30-35, 2003.

[5] Malhotra, R., Singh, N. and Singh, Y., "Design of embedded hybrid fuzzy control strategy for speed control of dc motor: A servo control case study", International Journal of Computer Applications, Vol. 6, No. 5, (2010).

[6] Lee, H-P and Yoo, I-E, "Robust control design for a twoaxis gimbaled stabilization system", in Aerospace Conference, IEEE. 2008, 1-7.

[7] B. Ekstrand,"Equation of Motion for a Two Axes Gimbal System", IEEE Trans. On Aerospace and Electronic Systems, vol. 37, pp. 1083-1091, 2001.

[8] Otlowski, D. R., Wiener, K. and Rathbun, B. A., "Mass properties factors in achieving stable imagery from a gimbal mounted camera", in SPIE Defense and Security Symposium, International Society for Optics and Photonics. 69460B- 69460B-13. 2008

[9] Zhen yu zhao ,Satura Isaka, "Fuzzy gains scheduling of PID ontrollers" IEEE transactions on systems Vol23 N5.1993 